\title{
Thermo-mechanical forging of 708M40 steel ring samples: experiments and modelling
}

\author{
Steven Hill ${ }^{1} \cdot$ Richard P.Turner ${ }^{2}$ (I) \\ Received: 25 February 2021 / Accepted: 22 June 2021 / Published online: 10 July 2021 \\ (C) The Author(s) 2021
}

\begin{abstract}
A series of ring compression tests using BS970:708M40 alloy steel samples were studied. These tests were conducted using a 2factor soak-temperature variable, namely $1030{ }^{\circ} \mathrm{C}$ and $1300{ }^{\circ} \mathrm{C}$, and a 4 -factor lubricant variable consisting of unlubricated samples, synthetic water-based, graphite water-based, and graphite and molybdenum disulphide viscous grease. The lubricant agents were all applied to the tool/billet interface. Process variables such as blow force and heating were controlled with the use of a gravitationally operated drop hammer and an automated programmable induction-heating unit. This matrix of the experimental parameters offered a sound base for exploring dominant factors impacting upon bulk deformation. This deformation was measured using fully calibrated equipment and then systematically recorded. A finite element modelling framework was developed to further improve the thermo-mechanical deformation process understanding, with finite element (FE) predictions validated through experimental measurement. Through the combined experimental and FE work, it was shown that temperature variation in the experimental parameter matrix played a larger role in determining deformation than the lubrication agent. Additionally, the use of synthetic and graphite water-based lubricants does not necessarily produce greater deformation when used in high-temperature forgings due to the lubricants breaking down, evaporating, or inducing rapid billet cooling as a result of the carrier used (water). Graphite-molybdenum disulphate grease far outperforms the other lubricants used in this trial in reducing friction and allowing deformation to occur across a die-face.
\end{abstract}

Keywords Forging $\cdot$ Ring compression $\cdot$ Lubricant $\cdot$ Deformation $\cdot$ Friction $\cdot$ Finite element

\section{Introduction}

\subsection{Review of the current literature}

Steels remain the most widely used structural material across industrial sectors [1] due to the raw-material availability, cost, in-service performance, and its ability to be manufactured, formed, machined, and shaped. 708M40 (4140) is a $1 \%$ chromium-molybdenum medium-hardenable general purpose high-tensile steel [2] increasing in its industrial usage. During metal-forming processes using $708 \mathrm{M} 40$ billets, such as rolling and forging, deformable manganese sulphide ( $\mathrm{MnS}$ )

Richard P.Turner

r.p.turner@bham.ac.uk

1 W.H. Tildesley, Bow St, Willenhall, West Midlands WV13 2AN, UK

2 School of Metallurgy \& Materials, University of Birmingham, Birmingham B15 2TT, UK inclusions become elongated. Such elongated $\mathrm{MnS}$ inclusions can have considerable adverse effects on mechanical properties, if the inclusions are not aligned with the loading direction [3]. Therefore, this must be considered and controlled when forging this alloy.

Bernd et al. [4] performed a two-stage forging process on AISI 4140 to deliver excellent mechanical properties. The first forging stage was conducted at $1200{ }^{\circ} \mathrm{C}$ to generate the bulk deformation and a secondary thermo-mechanical forming operation at $800{ }^{\circ} \mathrm{C}$ which resulted in reduced formability and increased required forming forces, but this was necessary to prevent grain growth and promote fine grain areas which deliver enhanced mechanical properties.

During forging, three types of recrystallization phenomena can occur: dynamic, static, and meta-dynamic recrystallization. The higher the processing temperature is, the more recrystallization is forced to occur within the microstructure of the metal, and the more the metallic billet will deform during each blow, without compromising the material strain rate [5]. Wan et al. [6] state that hot metal manufacturing processes 
involve high-temperature tribology. A class of hightemperature lubricants of inorganic polymers has been developed for hot metalworking operations. Borax-, silicate-, and polyphosphate additives are polymeric in nature; therefore, they deliver the appropriate friction and wear properties, allowing for a reduction in materials loss, increasing process stability and meeting ever-increasing surface quality requirements industrially. Polyphosphate salt is a costeffective lubricant that can adapt to a wide range of temperatures, whilst borate can impart very stable friction at the mating surfaces. Also, the addition of silicate additives embodies excellent restoration of rubbing surface with less friction. Within the literature [6], it is understood that problems can exist amongst graphite-based lubricants. The lubricating effect often deteriorates at elevated temperatures due to the contamination of water or other condensable vapours. Graphite enables the efficient lubrication at temperatures below $300{ }^{\circ} \mathrm{C}$

Friction effects in forging are usually represented mathematically as an interfacial shear stress using one of two possible models. The Coulombic model has traditionally been used in metal forming where friction is proportional to the normal pressure applied to a surface [7]. The second model is termed the interfacial friction factor, or shear friction model. Within the work considered here, friction is represented using the shear friction model, as a percentage of the material's shear yield strength.

Most forging operations require high pressures, due to the severity of deformation and material flow required [8]. The high pressures involved with a forging operation often result in an artificially high value of interfacial shear stress. In a real forging operation, the maximum shear stress must be less than or equal to half of the yield strength in order to be consistent with established yield criteria. This inconsistency explains why use of the shear model is often preferred in forging as it is based on the fact that when the material adheres or is 'welded' to a surface, the subsurface layers will plastically deform by shear [9].

Finite element modelling of the hot forging of steels has been studied both academically and industrially for a considerable number of years. Forging is a process that can be simulated effectively using commercial FE codes, due to the controlled and repeatable nature of the process, even at relatively fast forging rates. Typically, the modeller must decide prior to setting up an FE model what aspects are to be studied. This can be processing conditions, overall shape and deformation, microstructure evolution, thermal effects, or possibly focusing upon the tooling rather than the workpiece, to understand die life. Switzner et al. [10] used the FE code Sierra to predict thermal fields and as such estimate the microstructure and strength within stainless steel forgings. This allowed for recrystallization and as such flow softening to be included, thus more accurately predicting deformation behaviour, whilst, although for the nickel superalloy IN718, Ma et al. [11] studied FE modelling for global deformation behaviour. This work used the popular finite element code Deform3D, excellent for simulation of metal-forming operations, to predict global mechanical fields for a heavy forging of a flat billet in to a hemispherical shell component. They considered the ductile damage experienced by the billet, predicting this accumulation using the normalised Cockroft and Latham damage model. Peak damage was confined to edges, as would be consistent with surface and edge cracks. Kakimoto et al. [12] used the Cockroft and Latham damage model also to predict the likelihood of surface cracking within a billet. The Cockroft and Latham damage parameter is considered the most reliable out of all available damage models for metallic component bulk cracking behaviour.

Jang et al. [13] used an unnamed code to predict grain size evolution within the billet throughout the forging operation. Interestingly, this work used an arctangent function to describe the interfacial friction between workpiece and rigid die. Feng et al. [14] also used the Deform3D code to determine material flow characteristics within a dual directional hot forged gear. This work focused upon adjusting process parameters to optimise the final forging temperature, whilst also considering the mechanical fields within the part, typically using the effective stress, to understand stress distributions within the gear teeth.

\subsection{Motivation}

Industrially, drop-forging of steel components is in increasing demand, given its relatively rapid processing times, the wide range of geometries capable of being produced, and the thermo-mechanical work on the component yielding improved and work-hardened material. It is therefore of interest to industrial users the process to further their understanding of through-process deformation and temperature that a workpiece experiences. This can allow for operator prediction of the required thermal and mechanical best-practices such as if and when a re-heat is required, intermediate drop-forging dwell times to eliminate unnecessary cooling, successful operating temperatures, and lubricant agents. However, the current improvements and developments for drop-forging processing tend to be based upon shop-floor evidence and operator observations. Thus, there is a risk of identifying optimised processing conditions for different materials through iterative trials, often using complex component geometries, without fundamental understanding of the metallurgy and the mechanics. Furthermore, there is a risk of these best-practice methods and approaches being lost when a potentially ageing workforce retires. Thus, a motivation within the industry therefore exists to formulate a fundamental understanding of the thermo-mechanical drop-forging operation using a rigorous, repeatable set of experiments, and potentially through process 
modelling. This set of comprehensive experiments would ideally be performed using simple ring component geometry, so to better understand the mechanical and frictional effects of the key process variables, namely the hammer energy, the soak temperature, and the lubricant used.

The aim of this study is to measure the amount of deformation induced within ringed specimens machined from BS970 708M40 when a fixed force is applied to them using a gravity drop-forging hammer. Varying lubricant conditions (unlubricated, synthetic water-based lubricant, graphite waterbased lubricant, and graphite \& molybdenum disulphide grease) and soak-temperatures $\left(1030{ }^{\circ} \mathrm{C} \& 1300{ }^{\circ} \mathrm{C}\right)$ were used to assess their overall effectiveness in bulk deformation amount. FE modelling will allow for a greater understanding of frictional values at the interface region between the workpiece and the rigid tooling. Through improved understanding on the role played by the lubricants upon interfacial frictional conditions and thermal losses, so the forging process can be analysed in depth. This can allow engineers and forging experts to achieve required deformation fields in a controlled and repeatable fashion.

\section{Material}

$708 \mathrm{M} 40$ (4140) is a $1 \%$ chromium-molybdenum mediumhardenable general purpose high-tensile steel [2]. The alloy composition can been see in Table 1 . The additions of the micro-alloying elements $\mathrm{Cr}, \mathrm{Ni}$, and $\mathrm{Mo}$, improve this alloy's hardenability compared to low alloy steels [16], giving it a wider scope for differing applications and uses.

This alloy is used in most industry sectors for a wide variety of applications. Typical uses include drive shafts, couplings, bolts, and gears, together with many surface and subsurface components in the oil and gas industries. This grade also has reasonably good impact properties at low temperatures and can be good for some elevated temperature uses when compared to plain carbon steels. These benefits can only be obtained when in the heat-treated condition $[2,17]$. As the steel has a carbon content below $0.76 \%$, it is categorised as a hypoeutectoid steel. After forging, when cooling at slow rates such as air-cooling, this alloy forms a microstructure consisting of pro-eutectoid ferrite which forms at high

Table 1 Compositional range of chemical elements for 708M40 steel [15]

\begin{tabular}{lllllllll}
\hline Element & $\mathrm{C}$ & $\mathrm{Mn}$ & $\mathrm{Si}$ & $\mathrm{Cr}$ & $\mathrm{Mo}$ & $\mathrm{S}$ & $\mathrm{P}$ & $\mathrm{Fe}$ \\
\hline Min. wt\% & 0.36 & 0.7 & 0.1 & 0.9 & 0.15 & 0 & 0 & Bal. \\
Max. wt\% & 0.44 & 1.0 & 0.35 & 1.2 & 0.25 & 0.04 & 0.035 & \\
\hline
\end{tabular}

temperatures. At low temperatures, pearlite is formed in interlaying laths of eutectoid ferrite with cementite [18].

This alloy is generally supplied in the hardened and tempered condition in the tensile range of $850-1000 \mathrm{MPa}$ ( $\mathrm{T}$ condition) but can be heat-treated to achieve 700-1200 $\mathrm{MPa}$, dependent on section size ( $\mathrm{R}-\mathrm{W}$ condition) [2]. Austenite grain refinement is critical in achieving all of the abovementioned benefits [19]. Due to the wide range of sectors that $708 \mathrm{M} 40$ serves, global material equivalents have emerged with differing designations given to this material dependant on each country's classification system. It is also known as E19 (BS 970:1955), 42CrMo4 (European standard), 1.7225 (Werkstoff) or 4140/4142, B7, and L7 (SAE and AISI) [20]. When forging this material, numerous processing variables can affect its deformation rate and overall deformation amount. Three that can be considered the key process variables (KPVs) are the forging force applied to the object, the lubricated condition of the die/component interface, and the components' temperature.

\section{Experimental method}

A series of 36 ring compression tests were performed in total, across 8 varying process parameter conditions. These parameters included two billet soak temperatures of either $1030{ }^{\circ} \mathrm{C}$ or $1300{ }^{\circ} \mathrm{C}$. Then four differing parameters based around the lubricated condition of the component/tool interface were used. The lubricants used were 'unlubricated', 'synthetic water-based', 'graphite water-based' and a 'graphite-molybdenum disulphide grease'. All test conditions were repeated five times with the exception of the grease which was repeated three times. A breakdown of these tests can be seen in Table 2 below.

The material used was BS970 708M40 alloy supplied in the drawn round bright bar and hardened and tempered condition of ' $\mathrm{T}$ ' (248-302HB). The material was machined all-over on a computer numerically controlled (CNC) lathe to ensure all tests pieces were of the same size and surface appearance. The dimensional tolerance for each specimen was $\pm 0.2 \mathrm{~mm}$. After machining, each sample was engraved to ensure full traceability throughout the trial. Ring compression specimen sizes can be seen below in Fig. 1 .

In addition to ensuring the test samples were consistent, other variables were also required to be controlled such as billet heating, temperature measuring of the heated piece, lubricant application (amount and location), die temperature, and the impact force. An induction heating using $350 \mathrm{~kJ}$ of energy was used to heat each sample to 1030 ${ }^{\circ} \mathrm{C}$. This was delivered by a constant $5.4 \mathrm{~kW}$ of power for a duration of $65 \mathrm{~s}$. Alternatively $413 \mathrm{~kJ}$ of energy was used for each sample heated to $1300{ }^{\circ} \mathrm{C}$. A $5.5 \mathrm{~kW}$ of power was delivered for $75 \mathrm{~s}$ (Fig. 2c). Measurement of the heated 
Table 2 Process parameters for the series of 36 forging trials, at 8 different processing conditions

\begin{tabular}{llll}
\hline Sample & Soak temperature $\left({ }^{\circ} \mathrm{C}\right)$ & Lubricant & No. of repeats \\
\hline $1 \mathrm{U}$ & 1030 & Unlubricated & 5 \\
$1 \mathrm{~S}$ & 1030 & Synthetic water-based & 5 \\
$1 \mathrm{G}$ & 1030 & Graphite water-based & 5 \\
$1 \mathrm{GM}$ & 1030 & Graphite-molybdenum disulphide grease & 3 \\
$2 \mathrm{U}$ & 1300 & Unlubricated & 5 \\
$2 \mathrm{~S}$ & 1300 & Synthetic water-based & 5 \\
$2 \mathrm{G}$ & 1300 & Graphite water-based & 5 \\
$2 \mathrm{GM}$ & 1300 & Graphite-molybdenum disulphide grease & 3 \\
\hline
\end{tabular}

billet was performed with a fully calibrated pyrometer programmed at the same emissivity setting and measured from the same location each time.

The water-based lubricants were applied with automated spraying equipment (Fig. 2a). These were mixed five parts water to one part lubricant as per the manufacturer's data sheet. The mixtures were then measured using a hydrometer to ensure comparableness. The grease type lubricant was applied with a brush; this was performed in a representative manner similar to how it would be used in usual forging operations. Die temperature was measured with a fully calibrated pyrometer to ensure it was above $100^{\circ} \mathrm{C}$. This was necessary as the water-based lubricants work by evaporating the water carrier away allowing a thin lubricating film at the component/ tool interface. Each billet was placed onto the die in a consistent manner regarding travel time, promptness of blow, location, and environment. A consistent impact force was applied, using a gravity drop hammer, the 'Massey 2.2 MSC drop hammer', (Fig. 2d) owned by W.H. Tildesley Ltd. of Willenhall. The drop hammer works by allowing a 1150-kg tup to fall through gravitational acceleration from a predefined height. The drop distance can vary dependant on tool heights, but in this case, the total drop height when taking into account the top and bottom die was $1.65 \mathrm{~m}$ (bottom die shown in Fig. 2c). In additional to the tup weight, the flat top die that was fixed into the tup weighed $184 \mathrm{~kg}$, therefore giving a total mass of $1334 \mathrm{~kg}$. Thus, the system was calibrated to deliver $2200 \mathrm{~kg} . \mathrm{m}$ falling under gravitational acceleration, giving a blow energy of $\mathrm{E}=\mathrm{mgh}=21.5 \mathrm{~kJ}$. Each deformed billet was measured using a calibrated vernier caliper. All samples were measured repeatedly to ensure fair comparison.

\section{Finite element modelling}

In order to improve the understanding of the frictional conditions at the workpiece-tooling interface, the process was simulated using commercially available finite element (FE) software, Deform v11.3. The model was created to replicate the single-blow drop-forging performed in the experiment. Thus, a workpiece ring measuring the same size used experimentally, with an inner radius of $16.25 \mathrm{~mm}$ and an outer radius measuring $32.5 \mathrm{~mm}$, and a height of $20 \mathrm{~mm}$, was created, being forged in between two flat-bottomed dies. In order to expedite the simulation as much as possible, the model was calculated in a $2 \mathrm{D}$ axisymmetric mode.
Fig. 1 Dimensions for the ring compression samples

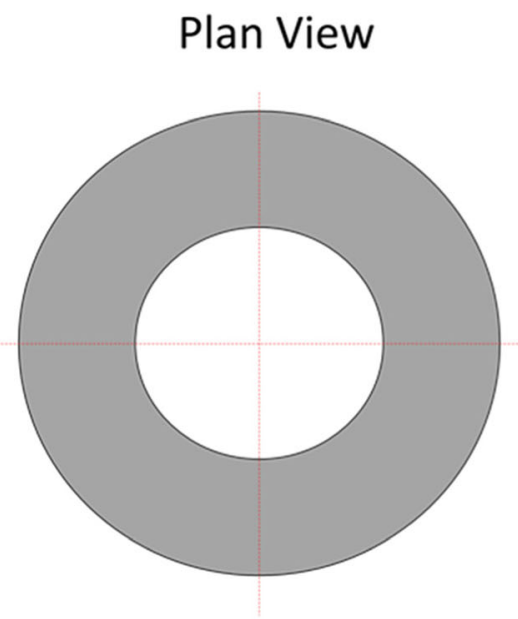


Fig. 2 a Water-based lubricant being applied. b Bottom fixed tool. c Sample being heated. $\mathbf{d}$ Drop hammer
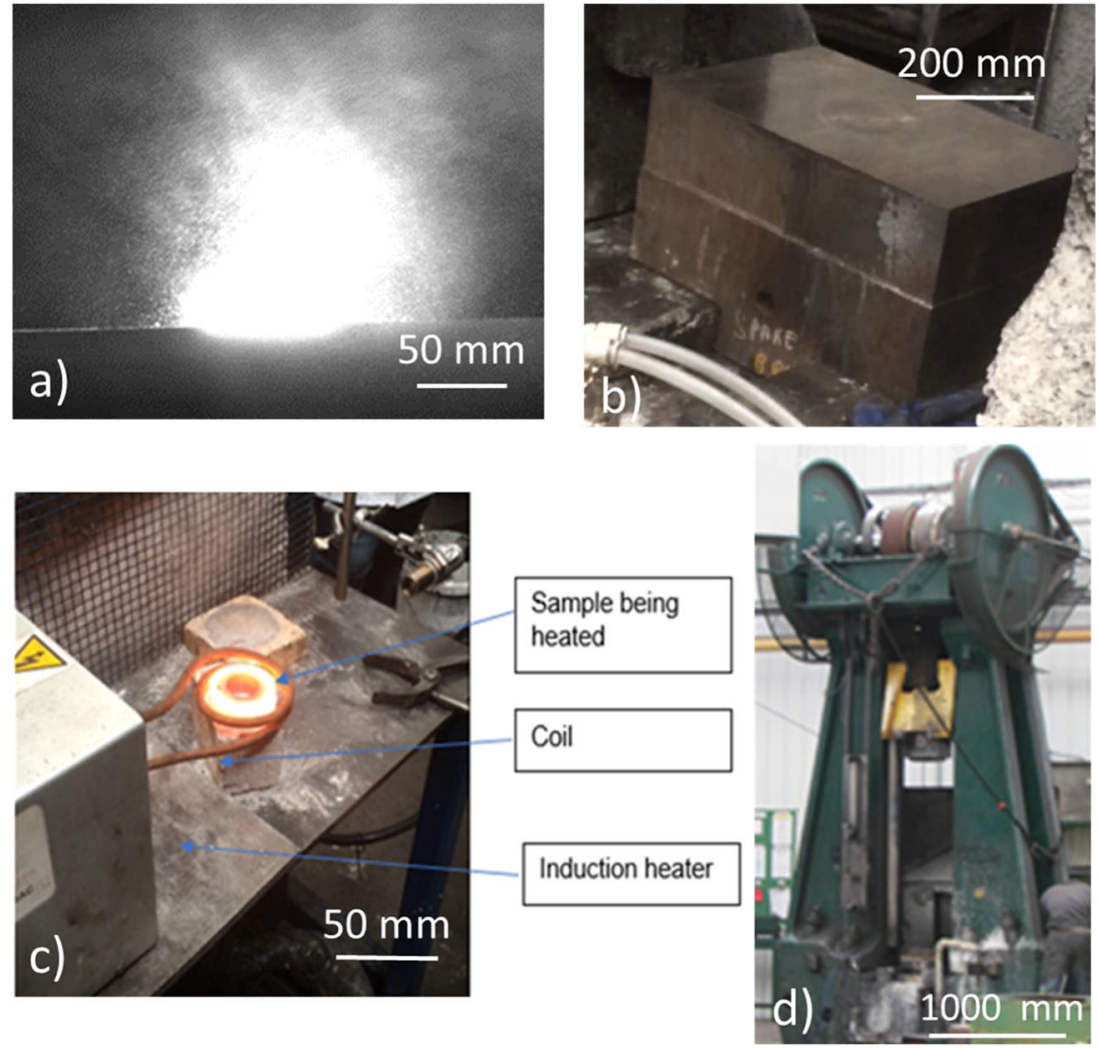

The model was ran in a fully coupled thermal-mechanical mode, and the workpiece was discretised using quadrilateral elements measuring from 0.25 - $\mathrm{mm}$ edge length at the surface to $0.75-\mathrm{mm}$ edge length in the centre of the workpiece. The dies were considered rigid, non-deformable objects. The setup of the FE simulation can be seen in Fig. 3.

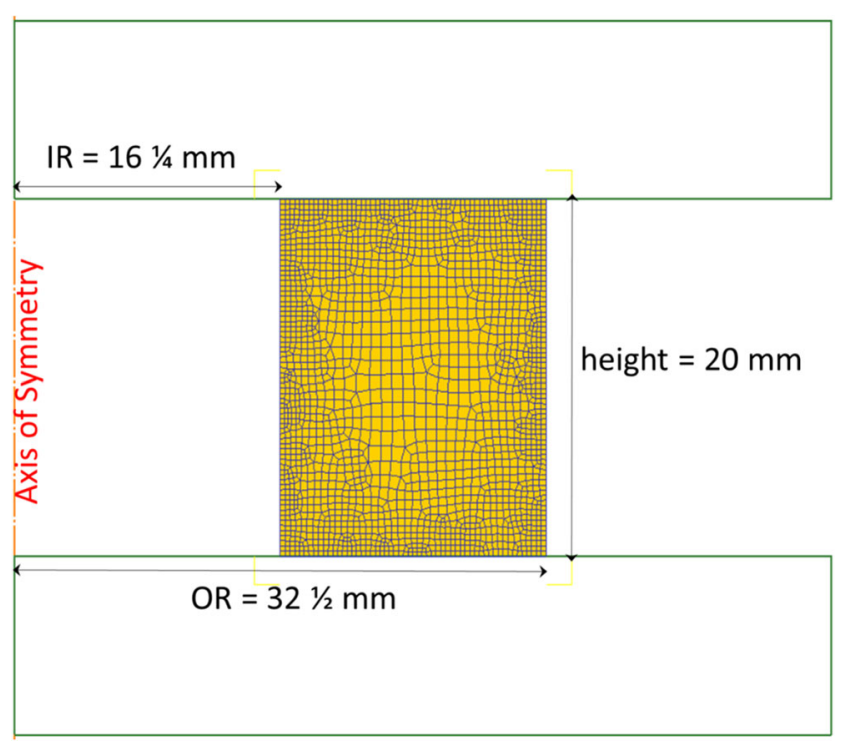

Fig. 3 FE modelling setup in the Deform2D/3D software, using a 2D axisymmetric model
The 708M40 steel material behaviour was represented in the FE model using a tabular flow stress data set, dependent upon strain, strain rate, and temperature; a temperaturedependent tabular data set for the Young's modulus, thermal conductivity, thermal expansion and specific heat capacity; constant density $\left(7850 \mathrm{~kg} \cdot \mathrm{m}^{-3}\right)$ and Poisson ratio $(0.3)$. Further FE simulation parameters were selected as appropriate, including a time-step of $0.001 \mathrm{~s}$, a heat transfer coefficient between workpiece and rigid tooling of $5 \mathrm{~kW} / \mathrm{m}^{2} . \mathrm{K}$, a convective heat transfer from workpiece to the atmosphere of 20 $\mathrm{W} / \mathrm{m}^{2} . \mathrm{K}$ and a workpiece emissivity of 0.7 . The workpiece is considered incompressible and follows an isotropic hardening law.

Thus, the only unknown remaining parameter within the modelling framework to represent the physical experiment was the frictional condition at the workpiece to rigid tooling interface. Malychev [21] states that whilst the coefficient of friction is often referred to as a simple material parameter, it should perhaps better be described as a system property, as it depends on a combination of both the billet and the tooling materials, and on external factors including velocity or rate of lateral deformation. By keeping all other conditions within the FE model the same, a systematic study of varying the shear frictional value at this interface allowed for an analysis of the sensitivity of the bulk deformation to the assumed friction condition. The shear friction law is given in Eq. 1, where $\mathrm{m}$ is the shear factor, $\mathrm{k}$ is the shear yield stress, and $g\left(v_{t}-\bar{v}_{t}\right)$ is -1 
when $v_{t}>\bar{v}_{t}$ and is 1 when $v_{t}<\bar{v}_{t}$, the relative velocity difference.

$\sigma_{s}=m \cdot k \cdot g\left(v_{t}-\bar{v}_{t}\right)$

Thus, by matching bulk deformation shape as accurately as possible, the frictional condition at the interface can be derived.

\section{Results}

\subsection{Shape}

Upon comparison of the forged rings for shape and deformation, there were negligible notable differences reported in the deformation observed for the unlubricated, water-based synthetic and the water-based lubricants, for the $1030{ }^{\circ} \mathrm{C}$ soak temperature forgings. All samples deformed to a similar geometry with the internal diameter decreasing to an average of $\varnothing 17 \mathrm{~mm} \pm 1 \mathrm{~mm}$ (for unlubricated), $\varnothing 19 \mathrm{~mm} \pm 1 \mathrm{~mm}$ (for water + synthetic lubricant) and $\varnothing 18 \mathrm{~mm} \pm 1 \mathrm{~mm}$ (for water + graphite lubricant). The outer diameter of deformed specimens for all lubricant conditions increasing to an average of $\varnothing 80 \mathrm{~mm} \pm 0.9 \mathrm{~mm}$, and the ring specimen height reducing to an average of $9.5 \mathrm{~mm} \pm 0.2 \mathrm{~mm}$ for unlubricated, synthetic, and graphite water-based lubricants. There is evidence of symmetric deformation on both the top and bottom surface of the sample (see Fig. 4a-c), suggesting that the lubricant condition was the same at both workpiece to die interfaces. This finding leads to an important design rule for the manufacturing engineer that the two water-based lubricants considered appear to have had no influence at all on the deformation at $1030^{\circ} \mathrm{C}$, when compared to unlubricated condition, whereas the graphite and molybdenum disulphide grease samples deformed differently. The internal diameter increased marginally to an average of $\varnothing 34.5 \mathrm{~mm} \pm 0.2 \mathrm{~mm}$, the outer diameter increased to an average of $\varnothing 95 \mathrm{~mm} \pm 3 \mathrm{~mm}$ and the thickness reduced to an average of $8.5 \mathrm{~mm} \pm 0.5 \mathrm{~mm}$. Note that the largest uncertainty by far in the deformation results was for the graphite and molybdenum grease outer diameter. This would suggest that a repeatable method of grease application is required, in terms of quantity and location of grease. This leads to the second
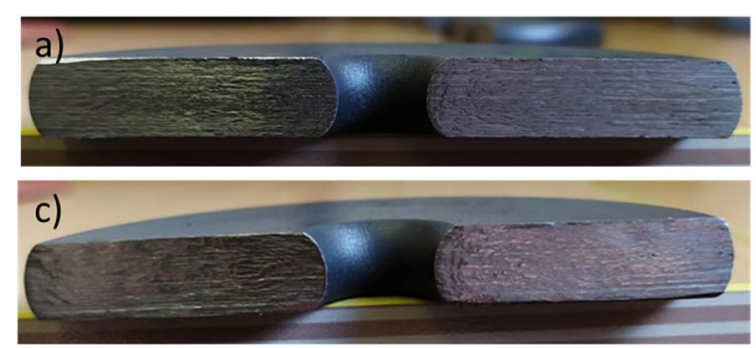

Fig. $41030{ }^{\circ} \mathrm{C}$ deformed samples: shape and outline design rule arising from the tests - uniformity and repeatability of the grease layer is of critical importance. The deformation also did not appear symmetric between the top and the bottom interface; more deformation appeared to be present on the top surface. Figure $4 d$ displays this. The stochastic analysis of the forging experiment's deformation mean values is reported in Fig. 5.

However, there was a more notable difference between the unlubricated samples and the two water-based lubricated samples at $1300{ }^{\circ} \mathrm{C}$. The unlubricated sample (Fig. 6a) actually deformed by a greater amount, its outer diameter increased to $89.8 \mathrm{~mm} \pm 8 \mathrm{~mm}$, its internal diameter decreased to $13.4 \mathrm{~mm} \pm$ $7 \mathrm{~mm}$ and its overall thickness reduced to $7.6 \mathrm{~mm} \pm 1 \mathrm{~mm}$. Note the considerably greater variation in results for repeat trials. This would suggest strongly that the repeatability of the experiment at the higher temperature is significantly less. This may be caused either by a poor repeatability of the induction-heating coil at these elevated billet temperatures or due to an uncertainty in the thermal monitoring for such high temperatures. A monitoring uncertainty would cause incorrect feedback within the induction coil control-system, and so potentially causing overheating of samples. As such, the third design rule generated by this experiment is to limit soak temperatures as much as possible.

The stochastic analyses of deformation measurements for $1300{ }^{\circ} \mathrm{C}$ soak temperature are presented in Fig. 7. There was negligible change between the mean deformation amounts and patterns for the two water-based lubricant samples at $1300{ }^{\circ} \mathrm{C}$. For both the water + synthetic lubricant and the water + graphite lubricant, the mean outer diameters increase to $86.1 \mathrm{~mm}( \pm 2 \mathrm{~mm})$, the internal diameter decreases to $11.2 \mathrm{~mm}( \pm 4 \mathrm{~mm})$ for the water + synthetic lubricant and $10.7 \mathrm{~mm}( \pm 4.5 \mathrm{~mm})$ for the water + graphite lubricant. The ring samples' overall height reduces to $8.1 \mathrm{~mm} \pm 0.2 \mathrm{~mm}$ for the water + synthetic lubricant, and $8.0 \mathrm{~mm} \pm 0.1 \mathrm{~mm}$ for the water + graphite. The resulting deformation trends are given in Fig. $6 \mathrm{~b}$ and $6 \mathrm{c}$. It is hypothesised that the water present in the lubricant is rapidly vaporising at these billet temperatures, which has potentially induced a different cooling rate caused by the agitated air during vaporisation, and ultimately, this additional cooling yields lower overall deformation. These samples' deformation outline was more consistent with the graphite-molybdenum grease sample (Fig. 6d).

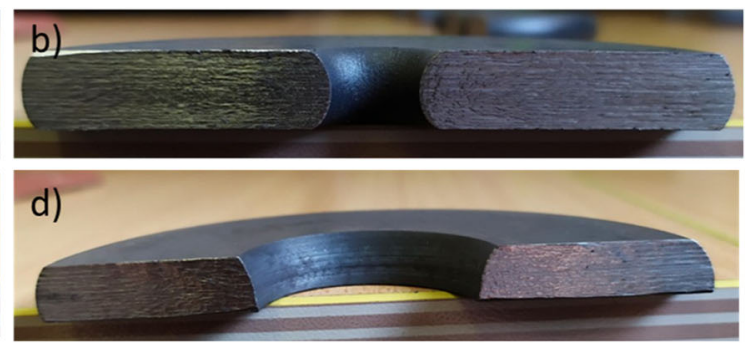


Fig. 5 Stochastic analysis of the deformation amounts measured for experimental trials at $1030{ }^{\circ} \mathrm{C}$; error bars show experiment standard deviation

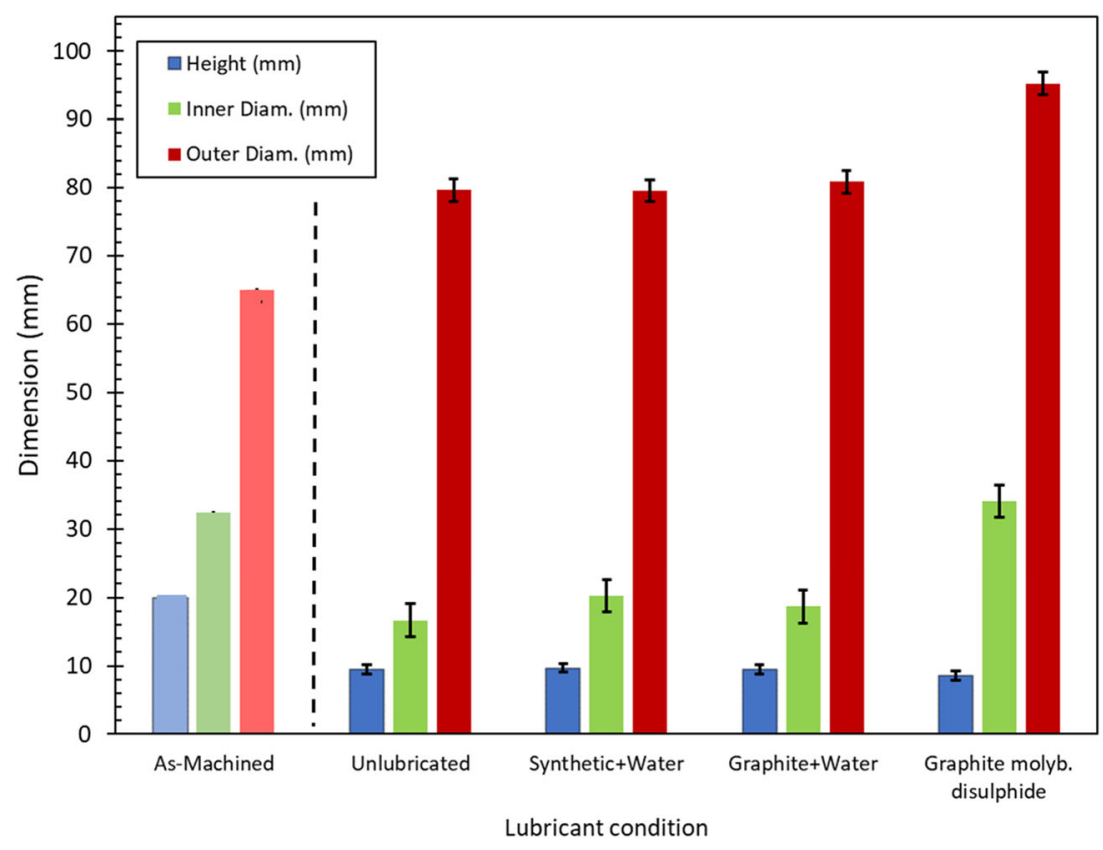

The graphite-molybdenum disulphide grease was again the most effective lubricant (Fig. 6d), evidenced by the additional deformation. In the other lubricant conditions at $1300{ }^{\circ} \mathrm{C}$, the internal diameter reduces, whereas for the graphitemolybdenum grease forgings, the internal diameter remains largely unchanged, with a mean of $\varnothing 32.5 \mathrm{~mm} \pm 0.2 \mathrm{~mm}$. The outer diameter of these samples increased much more than for other lubricants, with a mean of $\varnothing 97.6 \mathrm{~mm} \pm 1 \mathrm{~mm}$, and the sample height reduced to an average of $7.8 \mathrm{~mm} \pm 0.2$ $\mathrm{mm}$. As with the $1030^{\circ} \mathrm{C}$ graphite-molybdenum grease trials, the deformation again was not symmetric on top and bottom interfaces. However, as expected, all $1300{ }^{\circ} \mathrm{C}$ samples did deform to a greater amount than those samples deformed at $1030^{\circ} \mathrm{C}$.

\subsection{Lubricant application}

A further hypothesis concerning a manufacturing process design rule is considered. Is the forging deformation sensitive to any operator-related delay between applying lubricant and forging? To explore whether this had any effect on the deformation, a test was performed on a further two samples. Both samples were heated to $1030{ }^{\circ} \mathrm{C}$; one then had synthetic lubricant constantly applied whilst given one hammer blow. The other sample had graphite in water lubricant constantly applied. All other variables were kept in line with the previous trials. The arising deformation for these constantly applied water-based lubricants, compared to the deformation for the main experiment, where lubricant was applied once only, just prior to the forging, are shown in Fig. 8.

Figure 9 illustrates that between the singular graphite with water and synthetic with water applications, and constantly applied lubricant samples, the outer diameter remained relatively consistent. However, the internal diameter changed quite considerably from a mean of $18 \mathrm{~mm}$ on the singular lubricated sample to $20.5 \mathrm{~mm}$ on the constantly lubricated sample. The overall sample thickness varied from 9.5 to $11.5 \mathrm{~mm}$ respectively. One must therefore consider the role that temperature is playing on the forging behaviour of the steel. The constant application of lubricant does in theory increase the ability of the material to deform along the tooling interface. However, the lubricant is cold, being sprayed on to the heated billet. This allows for rapid cooling at the billet surface, an experimental variation when compared to the single-application lubricant tests; thus, by applying the cold lubricant, this may have actually hindered overall deformation.
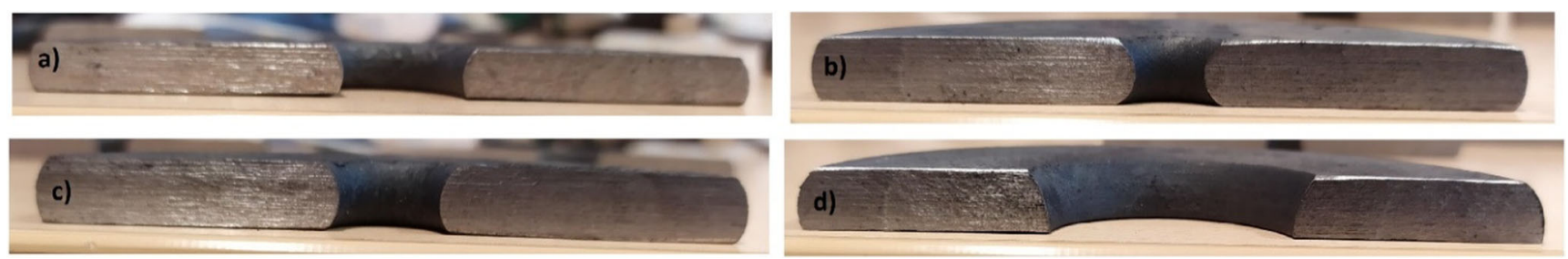

Fig. 6 Deformed sample shape and outline for forging experiments at $1030{ }^{\circ} \mathrm{C}$. 
Fig. 7 Stochastic analysis of the deformation amounts measured for experimental trials at $1300^{\circ} \mathrm{C}$; error bars show experiment standard deviation

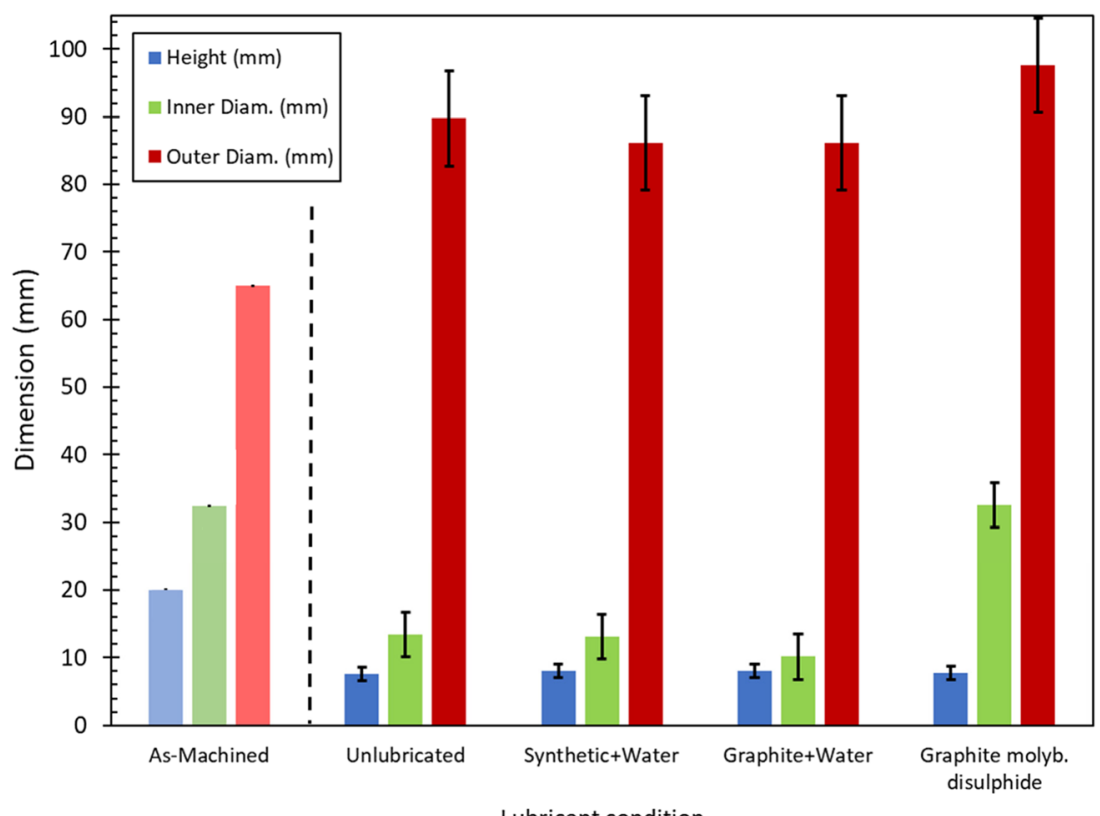

Lubricant condition

\subsection{Frictional interface condition}

Within the FE modelling framework, the shear friction parameter $\mathrm{m}$ was varied across a range of 0.08 to 0.7 , based upon prior work on the tribology and wear effects of metal to metal contact and lateral dragging, within the literature [21, 22]. Upon best-matching deformation shape, the unlubricated FE model was shown to correlate well with a frictional condition of $0.6 \sim 0.65$ on both the upper and the lower die interface, see Figure 10. This value does agree well with the coefficient of friction measured for steel-to-steel interactions in an unlubricated system arrangement [23].
For the forging using the graphite disulphide paste as a lubricating agent, the frictional interface conditions on the top and bottom surfaces clearly are not the same, hence the unequal amount of lateral sliding along these surfaces (if assuming equal die temperature). The optimal matching for the deformed shape was achieved with a coefficient of 0.5 applied to the top surface to upper die interface, indicating a slightly more lubricated interface than in the unlubricated model, whilst a coefficient of 0.2 on the bottom surface to lower die interface was used (see Fig. 11). The matching gradual arc of the outer wall of the ring was nicely matched, although the gradient of slope on the inner wall was not quite correct. This
Fig. 8 Graph comparison between singularly applied and constantly applied lubricant deformation at $1030^{\circ} \mathrm{C}$
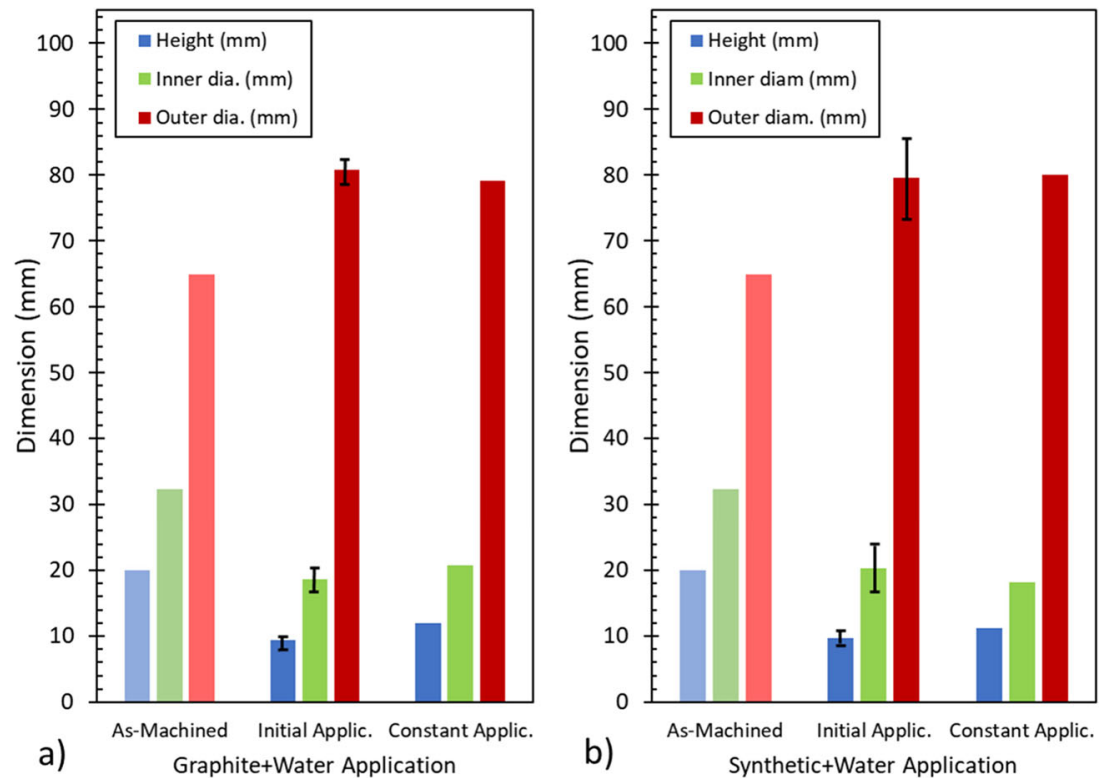

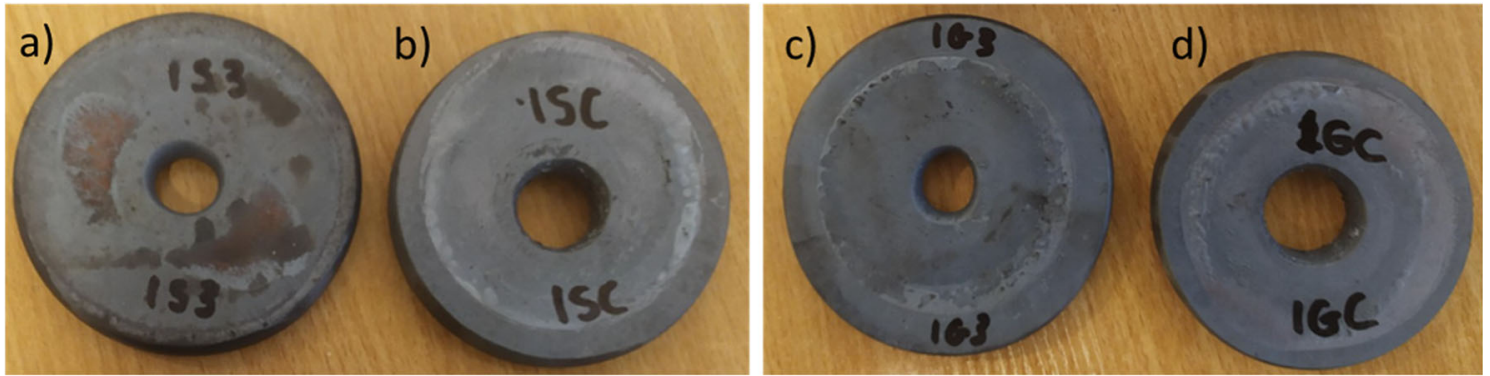

Fig. 9 Image comparison between singularly applied and constantly applied lubricant deformation at $1030{ }^{\circ} \mathrm{C}$

shape was improved further by increasing the lubricant effect experienced at the inner wall, using a coefficient of $0.05-\mathrm{a}$ highly lubricated condition. In reality, a non-uniform friction coefficient may still be plausible, for example, if a nonuniform coating of the paste was applied, or if the frictional value is temperature-dependent, and if any obvious differences can be seen in the temperature at inner and outer walls.

Due to the role that it will play in determining the interface frictional behaviour, surface roughness measurements were taken. It can be seen from Table 3 that the forging of these samples increased the surface roughness in the impression area by $36.79 \%$ for the bottom die and by $43.92 \%$ for the top die. Again, variation of roughness with location over the surface of the die may further suggest why a frictional coefficient may vary over an interface.

\subsection{Temperature}

Once the relevant frictional conditions at the interface, for the upper die to workpiece and lower die to workpiece interactions, were established through a systematic study, the forgings at an initial billet temperature of $1030{ }^{\circ} \mathrm{C}$ were interrogated further, to understand the thermal and mechanical fields generated within the thermo-mechanically processed billet. For the model representing the water-based lubricants, which were believed to have been effectively forged in an unlubricated condition due to vaporising of the lubricating agent, peak temperatures are clearly illustrated to be seen close to the internal surface of the ring specimen.
A temperature difference of approximately $60{ }^{\circ} \mathrm{C}$ was observed from outer to inner surface, with the billet heating due to shearing and internal work preferentially close to the inner surface (see Fig. 12), whereas for the FE model representing the graphite disulphide paste lubricant, a different thermal profile is observed, whereby the internal shearing and work heats a band of material propagating from close to the base on the specimen on the inner wall, to close to the top of the sample on the outer wall. This heating profile follows the typical strain bands that would be observed within a sample forging.

Whilst the temperature profile on the cross-sectional cut of the ring forging will be responsible for the bulk behaviour of the ring during forging, questions remain as to how the interfacial (upper and lower) surfaces of the billet impact the plastic deformation characteristics. There are a number of complex heating and cooling mechanisms influencing the surface temperature of the ring forging. The mechanical work, shearing the metal, wants to heat the component at various internal locations. The frictional heating as metal slides over tooling heats the exterior. The thermal conductivity of the steel sees the hot centre and tries to balance the component temperature by heating the surface from the centre, accordingly, whilst the surface cooling includes the heat loss to cold atmosphere, with a relatively low-heat transfer coefficient, and the die (heated but significantly cooler than the workpiece) applying a diechill constraint when in contact.

The duration that each of these heat-transfer mechanisms is applied for is also an important consideration. Internal heating through mechanical work and heat loss via upper die chill

Fig. 10 (Top) FE simulation of global deformation and shape, compared to the (bottom) experiment, for $1030{ }^{\circ} \mathrm{C}$ billet with unlubricated surface conditions

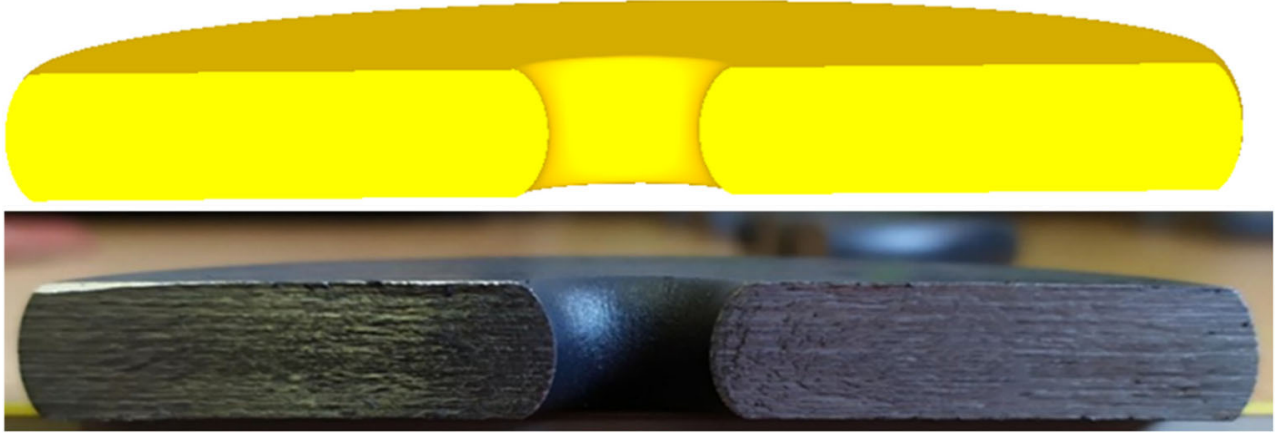


Fig. 11 (Top) FE simulation of global deformation and shape, compared to the (bottom) experiment, for $1030{ }^{\circ} \mathrm{C}$ billet with graphite disulphide paste applied to surfaces

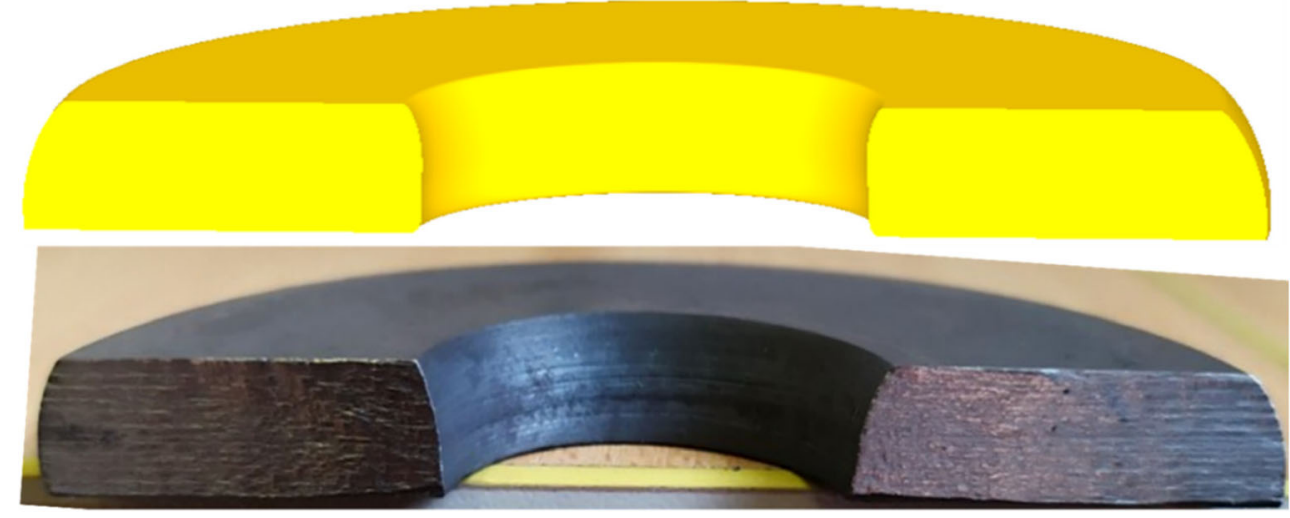

seem important, but the hammer is only in contact for a short time, compared to lower die chill, or to the thermal conductivity of the material constantly trying to rebalance the heat. The FE model was studied for these surface profiles, for the $1030{ }^{\circ} \mathrm{C}$ soak temperature forging, for an unlubricated and grease lubricated model, to get a better understanding of the surface temperatures at the interface regions (see Fig. 13).

The impact that these competing heating and cooling mechanisms have upon the surface of the ring workpiece becomes much more evident. Note that in the unlubricated condition (Fig. 13), the symmetry of the upper and lower surface is clear. Whilst there is a fraction more cooling against the lower surface due to fractionally longer contact, particularly at the inner diameter, this $25{ }^{\circ} \mathrm{C}$ difference has negligible influence upon flow stress. Whereas for the graphitemolybdenum disulphide grease model (Fig. 14), where friction coefficients were set differently on top and bottom dies, the thermal profile has become almost completely reversed. Instead of having some of the highest temperatures at the outer radius, there are now some of the lowest temperatures in the billet on the outer radius. The uneven friction conditions significantly affect the plastic deformation and therefore the shape of the ring forging, due to highly localised shear and associated heating.

\subsection{Cockroft and Latham normalised damage}

Lastly, the damage parameter used most frequently in the literature, the normalised Cockroft and Latham, was examined to determine whether any significant surface cracks or defects are predicted by the FE model. The resulting fields are displayed in Fig. 15. Note that in the unlubricated model, the distribution is fully symmetric, whereas in the model which simulated varying amounts of graphite disulphide lubrication on upper and lower surfaces, there is a thin region of more highly susceptible material to damage along the bottom surface, where the deformation, and so the strain, has been considerably greater than for the top surface of the billet.

\section{Discussion}

Visible differences in the deformation outline between the unlubricated and water-based lubricants were minimal. This is suspected to be due to the lubricants breaking down prior to the hammer blow being delivered. This conforms with literature [6], an assessment of graphite and the synthetic lubricants used was reported to only be effective up to temperatures of around $300{ }^{\circ} \mathrm{C}$. The heated billet would have been significantly higher than $300{ }^{\circ} \mathrm{C}$ when the lubricant was applied. In essence, all of the water-based lubricant samples were unknowingly at the time of forging in the unlubricated condition.

The graphite and molybdenum disulphide grease displayed higher deformation at the top of the sample when compared to that at the bottom of the sample. It is believed that the bottom die could have been acting as a heat sink on the sample therefore delivering a different temperature field across the part and facilitating differing amounts of plastic deformation.
Table 3 Measured surface roughness of the forging tooling prior to, and following, a single forging blow.

\begin{tabular}{|c|c|c|c|c|}
\hline \multirow[t]{2}{*}{ Die } & \multirow[t]{2}{*}{ Pre/post-forging } & \multirow[t]{2}{*}{ Surface roughness value (Ra) } & \multicolumn{2}{|c|}{$\begin{array}{l}\text { Increase in die surface roughness due to } \\
\text { forging blow }\end{array}$} \\
\hline & & & Absolute increase $(\mathrm{Ra})$ & $\%$ Increase \\
\hline Bottom Die & $\begin{array}{l}\text { Pre-forging } \\
\text { Post-forging }\end{array}$ & $\begin{array}{l}1.06 \\
1.45\end{array}$ & 0.39 & $36.8 \%$ \\
\hline Top Die & $\begin{array}{l}\text { Pre-forging } \\
\text { Post-forging }\end{array}$ & $\begin{array}{l}1.48 \\
2.13\end{array}$ & 0.65 & $43.9 \%$ \\
\hline
\end{tabular}




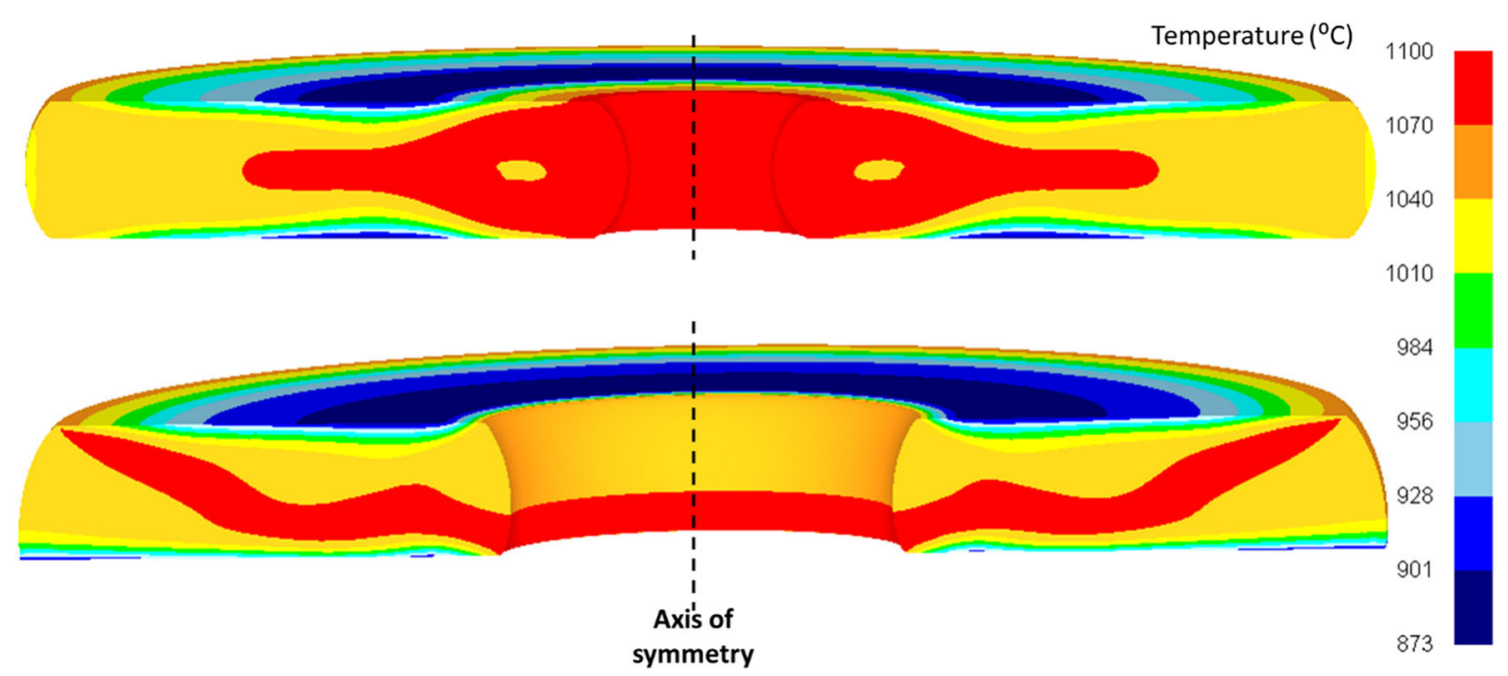

Fig. 12 Temperature distribution within the billets for the $1030{ }^{\circ} \mathrm{C}$ pre-heat, for (top) unlubricated, and (bottom) graphite disulphide grease lubricant.

However, if that reasoning were sound, it is therefore unknown why this deformation characteristic was not displayed on all samples. Further investigation into this phenomenon is required. A further hypothesis to explain this different deformation against the top and bottom dies is that the grease lubricant brushed to the bottom die adhered better than the top die allowing more flow to occur at the bottom of the sample.

The FE modelling predicted similar deformation variants at the top and the bottom with just frictional interface values to be varied. These variable top and bottom interface temperatures were studied in greater detail, with the annular thermal profiles being very similar in the symmetric distortion case, whereas a significant variation in annular thermal profile is observed in the non-symmetric graphite-molybdenum grease experiment. It would be of interest to further study different heat sink effects to better understand that effect, with a formal in situ thermal monitoring activity, which may prove useful to better identify the underlying mechanisms. However, it became evident that when considering the cross-sectional temperature profiles, for the intentionally and unintentionally unlubricated conditions, there is a greater temperature on the inner wall of the ring, with a difference of around $30-40{ }^{\circ} \mathrm{C}$ predicted. Whereas for the forging with an assumed uneven frictional coefficient top and bottom, caused either by lubricant application or by heat sink effects, a band of hotter material emanating from low down on the inner wall to high in the ring on the outer wall may lead to a softer material with lower flow stress and so there is preferential deformation at specific points.

The total deformation amount for $1030{ }^{\circ} \mathrm{C}$ was reasonably consistent amongst the unlubricated and water-based samples, due to the assumed vaporisation of the water in the waterbased lubricant tests, thus leaving the graphite or synthetic agent unable to be transported across the surface, and as such yielding a relatively unlubricated interface in each test, whereas, at $1300^{\circ} \mathrm{C}$, the variation across the unlubricated and waterbased lubricant conditions was more considerable. This could suggest that the vaporising of the lubricant media at the higher temperature creates additional thermal barriers, potentially through bubble formation, to change the heat transfer into the tooling. An alternative explanation for this difference in trend for the $1300{ }^{\circ} \mathrm{C}$ forgings is that at the higher workpiece temperature, a greater temperature measurement uncertainty using the pyrometer leads to increased inaccuracies regarding
Fig. 13 Upper and lower forging interface surface, showing thermal profile immediately after forging, for the $1030{ }^{\circ} \mathrm{C}$ unlubricated model
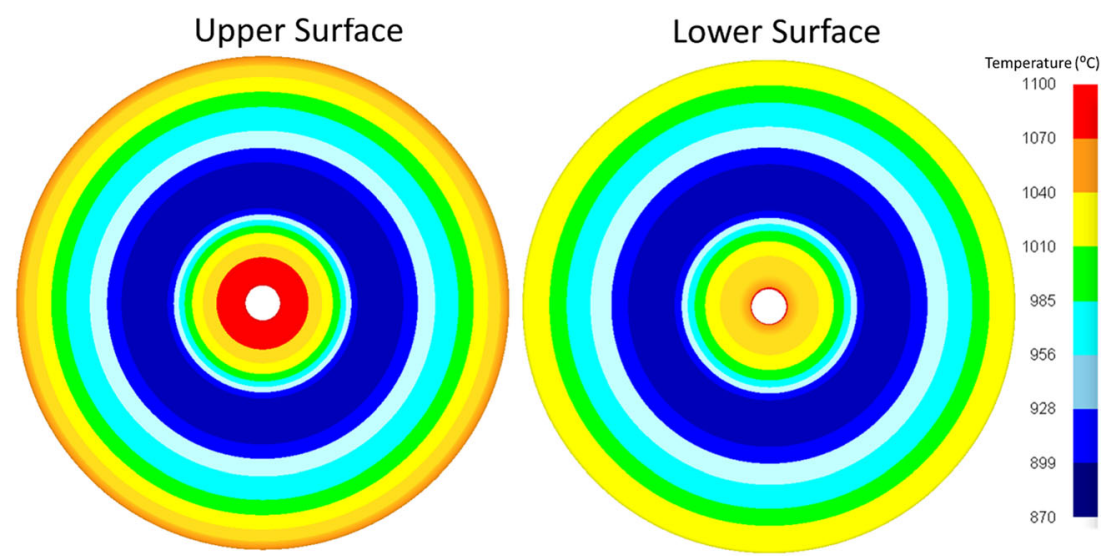
Fig. 14 Upper and lower forging interface surface, showing thermal profile immediately after forging, for the $1030{ }^{\circ} \mathrm{C}$ graphitemolybdenum grease model
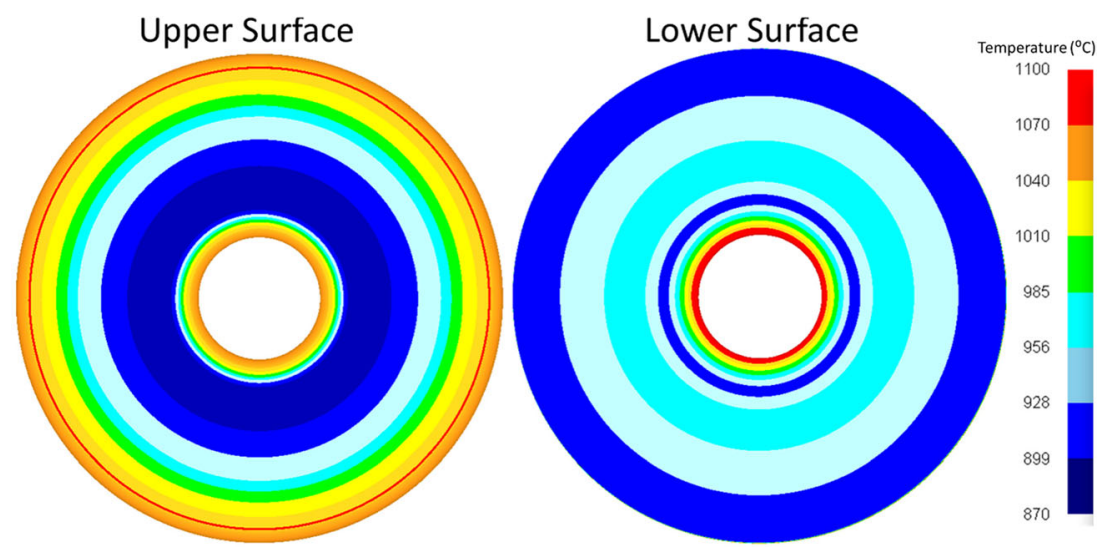

the true temperature of the workpiece; thus, greater temperature differences exacerbated the deformation variability.

The molybdenum graphite grease displayed a far higher deformation percentage at both $1030{ }^{\circ} \mathrm{C}$ and $1300{ }^{\circ} \mathrm{C}$ indicating it was far more effective in allowing the samples to plastically flow. For both the synthetic and the graphite waterbased lubricants, deformation amounts decreased compared to the initial experiments. Therefore, although it was believed that applying additional lubricant would allow additional material flow, this proved not to be the case. The reason for this result was as the water-based lubricant was being applied to the sample, it was inducing more rapid cooling than those samples in the original test, therefore increasing the material's yield strength and reducing its plastic flow amount under the same hammer blow impact.

To complete the study, an optimal lubricant condition is to be proposed, for further use during the drop-forging manufacture of this 708M40 steel. Given the negligible difference between the two water-based lubricants and an unlubricated condition at $1030{ }^{\circ} \mathrm{C}$, and even worse material flow for the water-based lubricants than for an unlubricated condition at $1300{ }^{\circ} \mathrm{C}$ - hypothesised to be due to vaporisation of the water - the graphite-molybdenum grease gives the best lubricating conditions at these hot forging temperatures. However, the considerable process variance observed in the measured deformation, the non-symmetric deformation on top and bottom surfaces, and the operator time taken to apply the grease significantly slowing down the process suggest that even if this is a sensible lubricant for use and research, a reliable application procedure is still required to be formally established.

\section{Conclusion}

A series of experimental forging trials using 708M40 ring specimens were performed, using different lubricant agents at the tooling to workpiece interface. Additionally, a 2D axisymmetric finite element model was created, to simulate the forging trials. The models systematically studied different frictional coefficients at the interface, in order to allow for global deformation and shape matching so to determine frictional coefficients in experiment. The following conclusions are drawn, which will help guide forging experts and

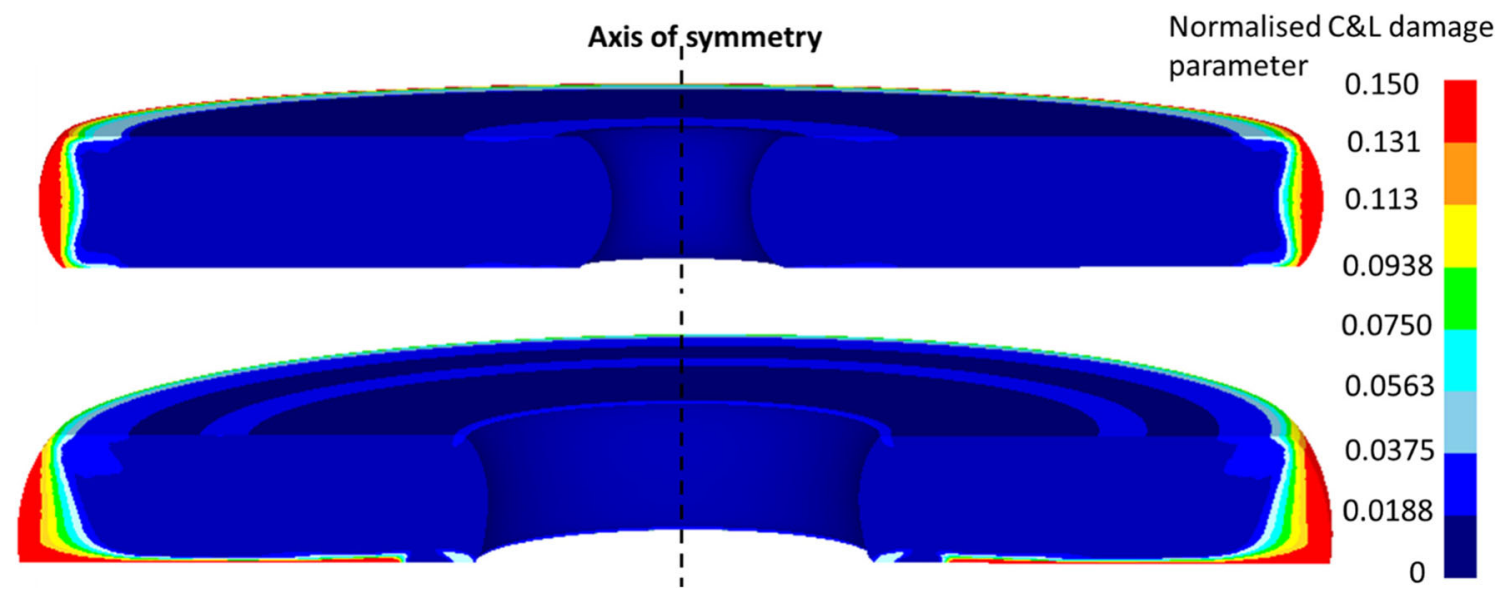

Fig. 15 Normalised Cockroft and Latham damage distribution within the billets for the $1030{ }^{\circ} \mathrm{C}$ pre-heat, for (top) unlubricated, and for (bottom) graphite disulphide grease lubricant 
manufacturing engineers toward an optimised drop-forging process for the $708 \mathrm{M} 40$ steel.

- The workpiece soak temperature from the inductionheating is the dominant factor in determining the amount of workpiece plastic deformation during a forging operation, with the hotter material deforming substantially more. However, the repeatability of the deformation was markedly worse at $1300{ }^{\circ} \mathrm{C}$. This is due to temperature control and monitoring limitations of the induction heater.

- The use of the two water-based die lubricants at $1030{ }^{\circ} \mathrm{C}$ does not appear to be effective in reducing friction at the tool/billet interface, as indicated by the negligible variation in deformation for the samples using these lubricants, compared to unlubricated conditions. In fact, at $1300^{\circ} \mathrm{C}$, the use of water-based lubricants gives worse material flow than the use of unlubricated ones, due to water vaporisation and changing heat transfer characteristics.

- Applying more water-based lubricant throughout the forging operation does not necessarily lead to increased workpiece deformation per each hammer blow, due to additional cooling effects at the surface. Thus, of these two competing mechanisms, the increase in flow stress at cooler temperatures proves the dominant influence in preventing deformation, despite a reduced friction coefficient.

- The use of graphite-molybdenum disulphide grease does effectively reduce friction at the tool/billet interface as the ring internal diameter grows from its original size. This was the most effective lubrication method considered. However, the frictional coefficient appears significantly different on top and bottom dies, which is likely due to insufficiently repeatable application methods.

- FE modelling has allowed for a validation of the frictional coefficients at the tooling to billet interface. In an unlubricated condition, a coefficient of $0.6-0.65$, and for the graphite-molybdenum disulphide paste, a value of 0.08 to 0.2 on the more lubricated bottom surface gives well-matched shape.

- FE modelling has illustrated the complex relationship that frictional coefficients at the workpiece interface have upon the internal shear, arising heating and cooling, and plastic deformation. Non-symmetric and non-uniform friction coefficients in the graphite-molybdenum grease forging model give rise to highly localised regions of shear, which has significant influence over all thermo-mechanical fields.

- Tool wear is shown to occur relatively rapidly, demonstrated by a significant increase in surface roughness Ra values measured before and immediately following dropforging. Thus, effective lubricants suitable to the forging temperature and materials should be sought to address this issue.
Code availability The Deform v11.3 Software code was commercially licenced.

Data availability FE modelling results are available.

\section{Declarations}

Conflict of interest The authors declare no competing interests.

Open Access This article is licensed under a Creative Commons Attribution 4.0 International License, which permits use, sharing, adaptation, distribution and reproduction in any medium or format, as long as you give appropriate credit to the original author(s) and the source, provide a link to the Creative Commons licence, and indicate if changes were made. The images or other third party material in this article are included in the article's Creative Commons licence, unless indicated otherwise in a credit line to the material. If material is not included in the article's Creative Commons licence and your intended use is not permitted by statutory regulation or exceeds the permitted use, you will need to obtain permission directly from the copyright holder. To view a copy of this licence, visit http://creativecommons.org/licenses/by/4.0/.

\section{References}

1. Smil V (2016) Still the Iron Age: Iron and steel in the modern world. Butterworth-Heinemann, Woburn (United Kingdom)

2. Abbey Forged Products (2021) 709M40: 1\%Cr-Mo steel. Available at: http://www.abbeyforgedproducts.co.uk/images/ downloads/PDF/709M40.pdf (Accessed: 20 January 2021)

3. Cyril N, Fatemi A, Cryderman B (2009) Effects of sulfur level and anisotropy of sulfide inclusions on tensile, impact, and fatigue properties of SAE 4140 steel. SAE International Journal of Materials and Manufacturing 1:218-227 https://www.jstor.org/stable/ 26282650

4. Behrens B-A, Brunotte K, Petersen T, Diefenbach J (2020) Mechanical and thermal influences on microstructural and mechanical properties during process-integrated thermomechanically controlled forging of tempering steel AISI 4140. Materials 13:5772. https://doi.org/10.3390/ma13245772

5. Wang L, Dongsheng Q, Guo J, Pan Y (2015) Austenite grain growth behavior of AISI 4140 alloy steel. Mechanical Behavior and Microstructure Evolution in Manufacturing Processes 5: 762890. https://doi.org/10.1155/2013/762890

6. Wan S, Tieu KA, Xia Y, Zhu H, Tran HB, Cui S (2016) An overview of inorganic polymer as potential lubricant additive for high temperature tribology. Tribol Int 102:620-635. https://doi.org/10. 1016/j.triboint.2016.06.010

7. Kossack C, Ziegert J, Schmitz T (2019) The sliding friction contact frequency response function. Procedia Manufacturing 34:73-82. https://doi.org/10.1016/j.promfg.2019.06.119

8. Olsen OT (1981) Estimation of friction factor and flow stress in forging processes. IFAC Proceedings Volumes 14(2):1861-1866. https://doi.org/10.1016/S1474-6670(17)63743-1

9. Nowak, J.D. (2014) Investigation of surface roughness and lay on metal flow in hot forging http://epublications.marquette.edu/ theses open/269. Accessed 1 Apr 2021

10. Switzner NT, Sawyer ET, Everhart WA, Hanlin RL (2019) Predicting microstructure and strength for AISI 304L stainless steel forgings. Mat Sci Eng A 745:474-483. https://doi.org/10.1016/j. msea.2018.12.054 
11. Ma Q, Lin Z, Yu Z (2009) Prediction of deformation behavior and microstructure evolution in heavy forging by FEM. Int J Adv Manuf Technol 40:252-260. https://doi.org/10.1007/s00170-0071337-9

12. Arikawa T, Kakimoto H (2014) Prediction of surface crack in hot forging by numerical simulation. Procedia Engineering 81:474-479

13. Jang Y-S, Ko D-C, Kim B-M (2000) Application of the finite element method to predict microstructure evolution in the hot forging of steel. J Mater Process Technol 101(1-3):85-94. https://doi.org/ 10.1016/S0924-0136(99)00460-4

14. Feng W, Jia X, Liu B (2020) Gao. M., Material flow characteristics and deformation law during dual directional hot forging of the steelaluminium spur gear. Proceedia Manufacturing 50:425-428

15. Kelvin Steels (2021) Technical specifications BS 970 708M40 (EN 19A). Available at: http://www.kelvinsteels.com/spec $708 \mathrm{~m} 40$. htm (Accessed: 20 January 2021)

16. Nagaraja HK (2020) Investigation of effect of mechanical properties and influence of heat treatment on AISI 4140 steel. IOP Conference Series: Materials Science and Engineering 1013(1):27. https://doi.org/10.1088/1757-899X/1013/1/012008

17. Atlas Speciality Metals (2021) Through-hardening low ally steel bar 4140. Available at: http://www.atlassteels.com.au/documents/ Atlas4140.pdf (Accessed: 20 January 2021).
18. Bhadeshia H, Honeycombe R (2017) Steels: microstructure \& properties, 4th edn. Butterworth-Heinemann, UK

19. Khani Sanij MH, Ghasemi Banadkouki SS, Mashreghi AR, Moshrefifar M (2012) The effect of single and double quenching and tempering heat treatments on the microstructure and mechanical properties of AISI 4140 steel. Mater Eng 42:339-346. https:// doi.org/10.1016/j.matdes.2012.06.017

20. Hillfoot (2021) Steel grade equivalents. Available at: https://www. hillfoot.com/steel-grade-equivalents (Accessed: 21 January 2021).

21. Malyshev VN, Chapter 8- Tribological aspects in friction stir welding and processing, in. Advances in friction-stir welding and processing, Woodhead Publishing Series in Welding and Other Joining Technologies, 2014, pp 329-386, https://doi.org/10.1533/ 9780857094551.329 .

22. Fuller DD (1956) Theory and practice of lubrication for engineers (2d. Coefficients of Friction), Wiley

23. Joun MS, Moon HG, Choi IS, Lee MC, Jun BY (2009) Effects of friction laws on metal forming processes. Tribol Int 42:311-319. https://doi.org/10.1016/j.triboint.2008.06.012

Publisher's note Springer Nature remains neutral with regard to jurisdictional claims in published maps and institutional affiliations. 